\title{
RECUPERACIÓN DEL PATRIMONIO INDUSTRIAL. ARQUITECTURA DEL HIERRO EN VALENCIA: GRANDES ALMACENES EL SIGLO VALENCIANO
}

\author{
Montiel Seguí \\ Universitat de València
}

\begin{abstract}
Resumen: El artículo realiza un estudio sobre la trayectoria de los antiguos grandes almacenes $\mathrm{El}$ siglo valenciano describiendo los momentos más significativos de su construcción, con los arquitectos Miguel Asensi, Joaquín María Arnau, Luís Ferreres, Javier Goerlich, y Vicente Momfort, como resultado del proceso adaptativo debido a las demandas de la sociedad de la época y de una nueva mentalidad empresarial. Finalmente, muestra las adecuaciones de salvaguarda, rehabilitación y adaptación para un nuevo uso, hoy Octubre Centre de Cultura Contemporània, que le han permitido llegar hasta nuestros días.
\end{abstract}

Palabras clave: Grandes almacenes, arquitectura industrial, hierro, rehabilitación, nuevo uso.

Recovery of industrial heritage. Iron architecture in Valencia: the old department stores El Siglo Valenciano

Abstract: The article makes a study on the trajectory of the old department stores El Siglo Valenciano describing the most significant moments of its construction, with the architects Miguel Asensi, Joaquín María Arnau, Luís Ferreres, Javier Goerlich, and Vicente Momfort, as a result of the adaptive process due to the demands of society of this period and of a new business mentality. Finally, it shows the safeguarding, rehabilitation and adaptation adjustments for a new use, today October Center de Cultura Contemporània, which have allowed it to reach our days.

Key words: Department stores, industrial architecture, iron, renovation, new use.

\section{INTRODUCCIÓN}

El objetivo de este trabajo es presentar los antiguos almacenes El Siglo Valenciano como ejemplo significativo de la nueva arquitectura, aprovechamiento y rehabilitación de un edificio catalogado como de arquitectura industrial que fue testigo de la profunda transformación social y urbanística que vivió Valencia junto a una novedosa construcción y diseño. En sus varias reformas trabajarán importantes maestros de obras y arquitectos que aplicarán a la tradición

Data de recepció: 15 d'abril de 2020 / Data d'acceptació: 11 de maig de 2020. 
constructiva nuevos productos prefabricados resultantes de un proceso industrializador.

Ubicado en un solar privilegiado con entrada y salida a dos calles: San Fernando $\mathrm{n}^{\mathrm{o}} 12$ y Cerrajeros $\mathrm{n}^{\mathrm{o}} 11$ de Valencia, fue uno de los primeros comercios que se abrieron en la ciudad como grandes almacenes de tejidos y de confección. "Los almacenes pioneros de la historia comercial española se abrieron en Madrid y en Barcelona, únicas ciudades, cuya densidad de población podía garantizar su éxito. [...] La mayoría de ellos nacieron como tiendas de tejidos y paulatinamente fueron incorporando artículos confeccionados [...]" (Toboso, 2002, p. 27).

El nuevo modelo de comercio se comenzó a gestar en París en la segunda mitad del siglo XIX extendiéndose por el resto de Europa y Estados Unidos. A manos del barón Haussmann (1809-1891), la capital francesa vivió una remodelación -acusada de maniobra imperialista napoleónica hacia el capitalismo financiero y de "especulación que roza la estafa" (Benjamin, 2005, p. 60)-, de la ciudad histórica y su entramado urbano medieval dirigiendo estas reestructuraciones hacia una expansión y transformación urbana provista de modernas infraestructuras, como harán las principales ciudades de España. Se abrieron grandes avenidas y circunvalaciones adaptando la ciudad parisina a las nuevas medidas higienistas y exigencias de comunicaciones. La organización de los barrios se modificó y los espacios públicos, bulevares, plazas, o los recién implantados passages adquirieron un lugar relevante en la ciudad moderna.

La mayoría de los pasajes de París fueron construidos en los quince años posteriores a 1822. La primera condición para su desarrollo es el apogeo del comercio textil. Hacen su aparición los almacenes de novedades, los primeros establecimientos que tienen constantemente en depósito una gran cantidad de mercancías. Son los precursores de los grandes almacenes. A esta época aludió Balzac cuando escribía: "El gran poema del escaparate canto sus estrofas de cobres desde la Madeleine hasta la puerta Saint-Denis". Los pasajes son centros para el comercio de mercancías de lujo. Con vistas a su decoración, el arte entra al servicio del comerciante. Los coetáneos no se cansan de admirarlos (Benjamin, 2005, p. 51).

El comercio burgués entró en los edificios apareciendo lo que conocemos hoy en día como grandes almacenes ${ }^{1}$. Muchos de las construcciones que estaban

\footnotetext{
${ }^{1}$ Los grandes almacenes son superficies dedicadas a la venta de una amplia variedad de artículos o bienes de consumo, deben su origen a una dinámica de producción en masa y a una sociedad que registra grandes cuotas de nivel de consumo. En la ciudad de Valencia existieron diversos grandes almacenes como El Águila, La Isla de Cuba, Montañés, Ernesto Ferrer y El Siglo Valenciano. Cerdá, Manuel y García Bonafé, Mario, 1995.
} 


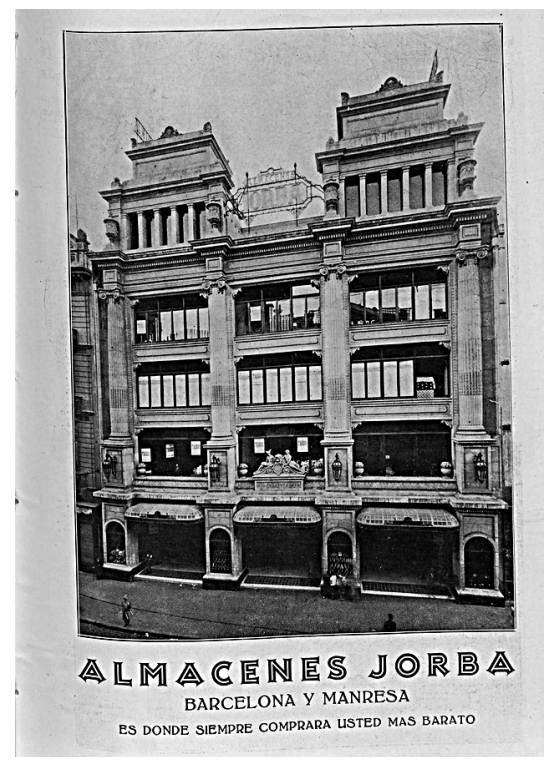

Imagen 1. Almacenes Jorba, Barcelona. Fuente: La Semana gráfica / revista ilustrada semanal de la región de Levante. Año V, número 163 - 24 agosto 1929.

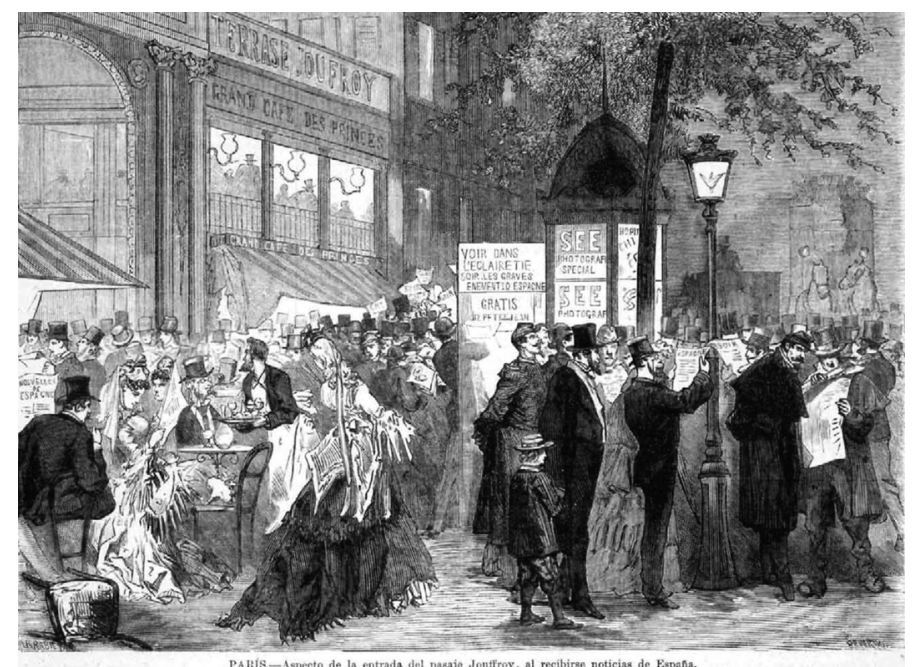

Imagen 2. Pasaje Jouffroy, París, 1872. Fuente: La Ilustración española y americana. BNE. 
destinadas a este acometido comercial amoldaron sus estructuras a las nuevas necesidades que este requería, a modernas formas de vender el producto, a las novedosas maneras de exponer la mercancía, donde el cliente, principalmente la mujer, era partícipe directo circulando libremente por una atmósfera que lo integraba y donde los dependientes le ofrecían una atención personalizada.

Toda la organización interior de los grandes almacenes posibilitaba la actividad comercial. "Los grandes almacenes son los primeros comercios que rompen con el concepto de tienda tradicional. Hasta su aparición el comercio detallista se practicaba en pequeños establecimientos familiares, actuaba en un ámbito local reducido y estaba especializado en la venta de mercancías concretas." (Toboso, 2002, p. 8). Según Serrano Saseta (2006), tres fueron los espacios más importantes dentro de un gran almacén parisino: "La galería, el hall y la sección o departamento (rayon en francés)".

La galería era el espacio lineal de reunión reservado para el cliente, con mostradores a ambos lados donde el dependiente hacía de intermediario entre la clientela y el género expuesto de manera vertical tras él. La galería irá evolucionando según el almacén se vaya desarrollando, ampliando el área de trato entre el cliente y el género.

Según el autor, en el esquema tipo departamento, "los elementos de clasificación, los mostradores, los muebles y objetos que llenan el espacio se han situado perpendicularmente a la dirección de recorrido del visitante, generándose pequeñas células habitables, en las que comprador y vendedor se relacionan sin ningún obstáculo entre ellos".

En el tipo hall central, el edificio se abre sobre sí mismo para admirarse. Se divide en dos tipos hall-calle y hall-plaza, dependiendo de la manera en que funcione el comercio. El hall-calle lo hace en línea, en consonancia con la galería; mientras que el hall- plaza se muestra en sentido de contemplación vertical y horizontal, con calles y manzanas ocupadas por mostradores, donde la iluminación irradia fuertemente con grandes claraboyas sobre el encuentro social en la parte baja del recinto.

Dentro de este marco de referencia, es importante relacionar la forma de la ciudad con sus edificios y la cultura que los produce. "Para que los grandes almacenes se desarrollaran era necesario que los vecinos pudieran acceder con facilidad a las zonas comerciales, generalmente situadas en el centro de la ciudad" (Toboso, 2002, p. 8).

El edificio de El Siglo Valenciano será testigo directo de los nuevos planes urbanísticos llevados a cabo en Valencia tomando de referencia otras ciudades europeas, como fue París y Barcelona, de manera que su emplazamiento quedará inmerso en un nuevo remodelado de la urbe, en una zona céntrica de fácil accesibilidad. 


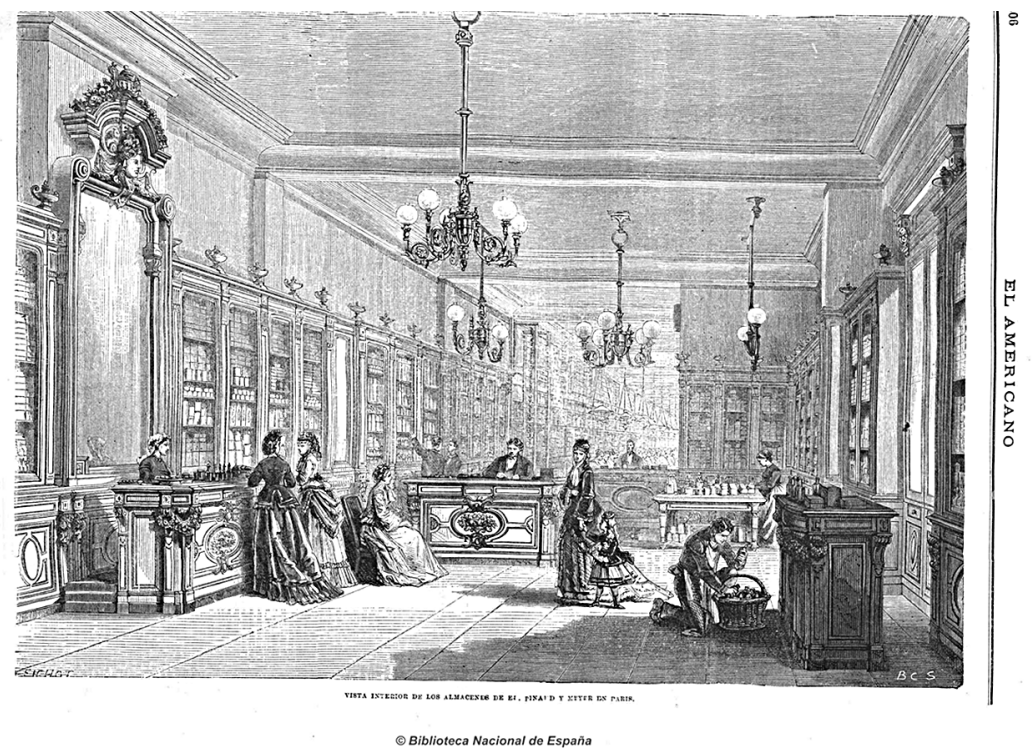

Imagen 3. Almacenes Pinaud y Meyer, París, 1873. Fuente: La Ilustración española y americana. BNE.

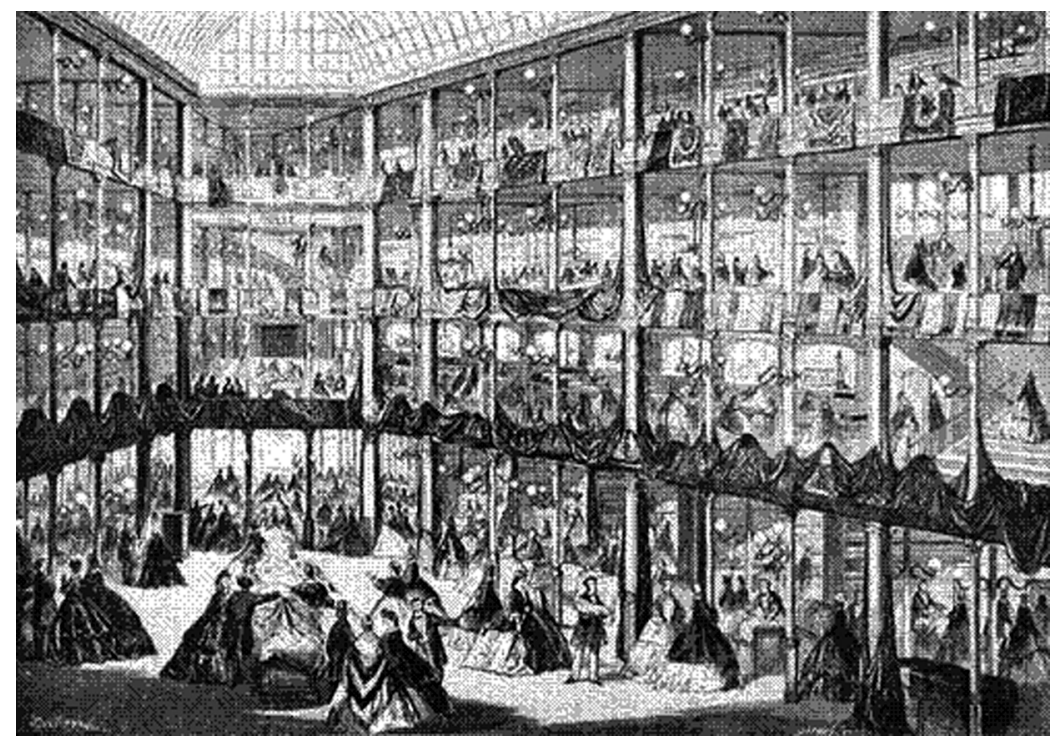

Imagen 4. Grandes almacenes Au Coin de Rue, hall central, 1860 (Serrano, 2006). 
La década comprendida entre 1833 y 1865 se caracteriza por una gran actividad constructiva controlada por el Reglamento de la Policía Urbana donde hay libertad de intervención privada, la Real Junta de Policía Urbana se encarga de poner en marcha las mejoras urbanísticas, así como un avance en las comunicaciones y el transporte -Ley de Carreteras del 7 de julio de 1851- (Palacio, 1998, p. 339). La moderna ciudad derribará las murallas que le impiden su crecimiento, en 1865; el nuevo hombre será el protagonista de "el advenimiento de la era maquinista" (Carta de Atenas, 1933 citado en González-Varas, 2008, p. 345); las fábricas ocupan los solares desamortizados en 1836 y 1835 (Pingarrón, 2005). La Real Pragmática (1707-1804) suprimirá los fosares dentro de la ciudad, en la zona del mercado desaparecen los cementerios de san Martí y santa Catalina (Teixidor, 1976) (Callado, 2014, p. 292) permitiendo ocupar su suelo nuevas construcciones. Se controla la alineación de las calles, el alzado de edificios según el ancho de la calle -16 metros las de primer orden- de acuerdo a la Real Orden del 10 de junio de 1854 (Taberner y Broseta, 2013, p. 189), construcción de aceras, el empedrado de estas que permiten el paso peatonal y el tránsito más fluido, a la vez que una adecuada limpieza pública. Tres centros neurálgicos se están formando en Valencia, los almacenes El Siglo Valenciano se crearán en uno de ellos, el que abarca la recién abierta avenida María Cristina, el Mercado Central y la calle San Vicente junto al nuevo Ayuntamiento. La ciudad va modernizándose, en 1849 Valencia dispone de 324 farolas, 1.600 luces particulares que alumbraban el teatro, academias, muchas tiendas y establecimientos, el Ayuntamiento y el gobierno político (Quirós et al., 1991, p. 51). El Plan de Ensanche, aprobado definitivamente en 1887 sobre el proyecto presentado en 1884 por los arquitectos Josep Calvo, Lluís Ferreres y Joan María Arnau, establece los ejes de las Grandes Vías: Fernando el Católico, Germanías y Marqués del Turia. La avenida diagonal será la Avenida Victoria Eugenia (actual Reino de Valencia). La nueva ciudad seguirá el modelo urbanístico de ensanche del Plan Cerdà de Barcelona (1859).

Los almacenes El Siglo Valenciano se escenifican, dentro de su ámbito histórico, como escaparate de la nueva sociedad burguesa. El proyecto conjugaba las exigencias de una sociedad que comenzaba a modernizarse y promocionarse a través de los nuevos medios gráficos de publicidad, ofreciendo diversidad de mercancías que se vendían al por menor, mayor cantidad de los productos y economía de costes. La nueva mentalidad consumista, gran parte de ella de procedencia agraria, demandaba los productos que en los almacenes se exhibían y vendían; productos realizados en cadena resultado de un conjunto de inventos y mejoras técnicas. Las innovaciones tecnológicas de la Revolución Industrial se aplicarán a la producción. El comercio rápido se acrecienta, el in- 
terés privado estimula la ley de oferta y la demanda, esta instiga la competencia, las máquinas sustituyen el trabajo artesanal entrando en decadencia el pequeño comercio.

Gaujean, el fabricante de sedas, metió entonces baza en la conversación y el tono de las voces volvió a bajar. Acusaba a los grandes almacenes ${ }^{2}$ de estar arruinando a los fabricantes franceses. Había tres o cuatro que les imponían su ley, que campaban a sus anchas en el mercado; y dio a entender que el único modo de combatirlos era favorecer a los pequeños comerciantes, a los especialistas, que eran quienes realmente tenían futuro (Zola, 1999, p. 11).

Tras la caída del comercio de la seda, el sector textil, de mayor tradición en el ámbito valenciano, se reinventa introduciendo nuevos edificios, actuales fuentes de energía y moderna maquinaria pasando directamente de la máquina a la fábrica (Aguilar,1990, p. 53). El trabajo se concentrará en un único punto de producción: los edificios industriales, y no en los hogares individuales.

Cataluña aparece como pionera de esta modernización industrial, superando con posterioridad la producción lanera de Béjar (Quirós, Coello y Guesdon, 1991, p. 24). En la Comunitat Valenciana emergen conatos industriales en la ciudad de Alcoi, el Comtat y en la Vall d'Albaida (Cerdá y García, 1995, p. 592).

Este artículo sintetiza el conjunto de estos cambios desde las primeras noticias de fábrica de El Siglo Valenciano en el año 1855, con arquitectos de la talla de Miguel Asensi, Joaquín María Arnau, Luis Ferreres, Javier Goerlich y Vicente Momfort que realizan un trabajo de funcionalidad y adaptación a un nuevo mercado, empleando para ello nuevos planteamientos estructurales. Las arquitecturas comerciales que se estaban llevando a cabo en el resto de Europa durante el siglo XIX influirán decisivamente en la estética y morfología del edificio estudiado. El espacio comercial disponía de una gran diafanidad e iluminación de hábil resolución debida al empleo de los nuevos elementos estructurales, hierro y vidrio, permitiendo ver a primera vista los productos expuestos. Su moderna conceptualización y organización -inspirada en modelos como el de los grandes almacenes Au Coin de Rue (imagen 4) con patio central como eje de los diferentes tres pisos de galerías abiertas y que hoy en día mantiene-, lo convertirán en el "gran almacén" del centro de Valencia. La arquitectura industrial resulta de la utilización de nuevos materiales junto a los antiguos de forma novedosa, el hierro será el gran protagonista de la arquitec-

${ }^{2}$ Los imaginarios grandes almacenes en los que Zola crea la trama de la novela, publicada en 1883, están inspirados en los primeros de París: Pintemps, Bon Marché o el Louvre, entre otros. 


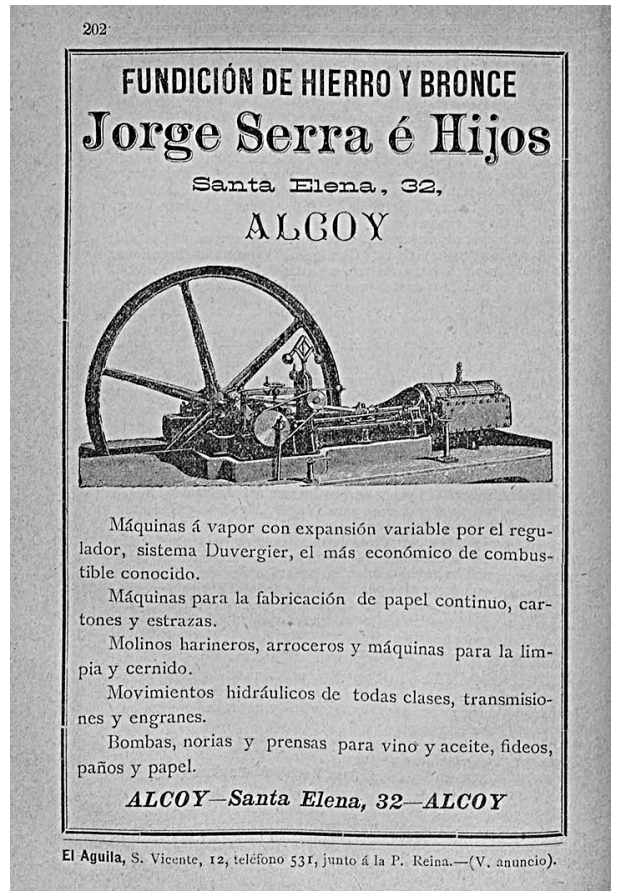

Imagen 5. Fundición Serra e Hijos, Alcoy. Almanaque de las Provincias para el año 1896, p. 202. Fuente: BIVALDI.

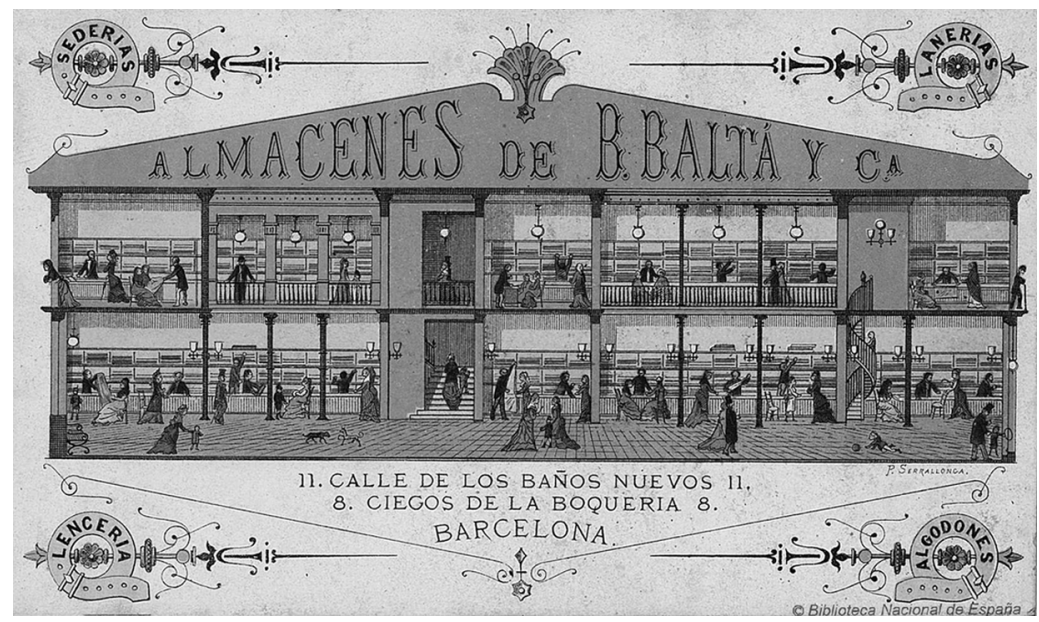

Imagen 6. Cromolitografía de los Almacenes de B. Balta y Cia. Barcelona. Columnas de fundición sustentantes. Fuente: BNE. 
tura del siglo XIX que busca nuevas dimensiones en sus espacios interiores, mejor iluminación, así como diafanidad e higiene (Aguilar, 1990).

Diversos congresos son celebrados en Barcelona y Zaragoza entre 18811919, donde se discute sobre la decadencia de las artes, la cultura arquitectónica historicista y sobre el ideal arquitectónico. Se cuestiona el valor de lo bello y lo sublime ante la aparición de materiales que no son extraídos de la tierra ni de los árboles sino de las fábricas. Josep Domènech i Estapá (1858-1917), arquitecto de la escuela de Barcelona, reconoce las posibilidades del hierro en la arquitectura como elemento útil capaz de crear un estilo propio, y llama a los arquitectos a dotarlo de una condición estética. Joaquín Bassegoda (1974), por lo contrario, considera el hierro como un elemento auxiliar sustentante. Los congresos determinan que no consideran la arquitectura del hierro como un nuevo estilo, pero reconocen que este material facilita el utilitarismo, abarataba costes y dota a la arquitectura de una aparente riqueza. Las ideas estéticas e ideológicas del siglo XIX configuraron una rehabilitación arquitectónica historicista medievalista (Isac, 1987).

La columna de hierro fundido, resultado de la revolución tecnológica, se inspirará en los modelos clásicos; esta se compone de: basa, fuste y capitel. Cada una de esas partes se adapta a requisitos de la construcción, adoptando novedosos modelos que estilizan sus fustes como soporte, acomodando de modo caprichoso sus capiteles, y convirtiendo el arte dórico en símbolo de la arquitectura más pura. En los modelos más primitivos encontramos la columna y el capitel formando un conjunto único. Fue habitual para las fachadas de los comercios utilizar el hierro, de manera que en Francia, Estados Unidos, o Inglaterra este material quedaba asociado a los edificios comerciales (Hitchcock, 1993, p. 191).

Aparecen nuevos materiales en esta época, se abarata el precio del vidrio plano para las ventanas, aparecen los lucernarios con vidrieras artísticas de diversos motivos para cerrar amplios espacios, se ponen de moda los balcones de hierro, las fachadas se pintan con nuevos materiales y comienzan a surgir los miradores para mirar sin ser vistos "que constituirán un elemento nuevo de las viviendas de la alta burguesía [...] con fuerte implantación en el ensanche de Colón, en donde va a ver una abundante implantación de la vivienda de las clases mas acomodadas" (Taberner y Broseta, 2013, p. 189).

Aunque en las construcciones continúa utilizándose la piedra, ladrillo y la madera, la funcionalidad del hierro hará que se introduzca fácilmente en la construcción. 


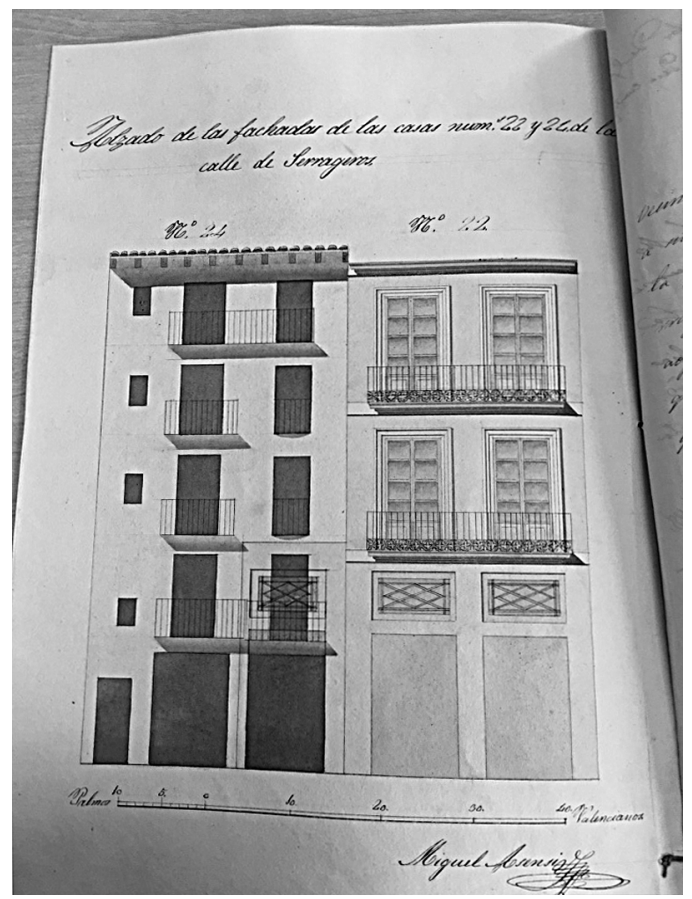

Imagen 7. Fachada calle Cerrajeros, 1855, Miguel Asensi. Fuente: AHMV.

\section{PROYECTOS CONSTRUCTIVOS: PRIMERAS ARQUITECTURAS}

El documento más antiguo que conocemos sobre el edificio El Siglo Valenciano es de $1855^{3}$, en el que la puerta principal de entrada al recinto aparece sita en la calle Cerrajeros. En este escrito, el maestro de obras Miguel Asensi solicita al Ayuntamiento permiso para remodelar las fachadas comprendidas en dicha calle entre los números 22 al 24, propiedad de D. Jorge Miralles.

Como podemos observar en la imagen 7 se trata de la ampliación del bajo de la casa ubicada en el número 22 hacia la casa número 24 . Nuevamente, será en $1866^{4}$ cuando se solicite permiso para realizar obras en las fachadas de la calle Cerrajeros bajo la mano del mismo maestro de obras y el mismo propietario.

3 Archivo Histórico Municipal de Valencia (AHMV). Serie: Policía urbana, año: 1855, caja: 83 (100), no expediente: 47.

4 Archivo Histórico Municipal de Valencia (AHMV). Serie: Policía urbana, año: 1866, caja: 103 (128), nºxpediente: 89 . 
En el siguiente año, en $1867^{5}$, nuevas modificaciones atañen a la misma fachada:

El que suscribe maestro de obras de esta vecindad expone que las casas $\mathrm{n}^{\circ} 20$ al 28 de la calle Cerrajeros propiedad de don Jorge Miralles vecino de Barcelona tiene a su cargo construirlas de nuevo según el adjunto proyecto que acompaña, en el cual lo marcado de carmín [los siete vanos del piso superior; los cuatro primeros de la hilera de en medio desde la izquierda hacia dentro; y los cuatro que recaen bajo estos últimos] es lo que se ha de construir de nuevo y lo de tinta lo que existe en la actualidad.

Finalmente, la fachada de la calle Cerrajeros quedará unificada en una sola casa constituida por una planta baja y tres alturas con siete vanos cada una, alzado que se mantiene en la actualidad.

Un albarán de la empresa Jorge Miralles y Cia. facturando vara y media de fieltro, fechado en Valencia a 14 de diciembre de 1860, además de orientarnos del oficio de la venta de telas ${ }^{6}$ nos indica un cambio de denominación de la empresa.

El 18 de diciembre de $1901^{7}$, volvemos a encontrar intervenciones en dicho edificio cuando el arquitecto $^{8}$ y urbanista Joaquín María Arnau Miramón (18491906) pide permiso para realizar varias obras en las casas número 17 al 23 de la calle San Fernando, indicando que el edificio tiene otra fachada recayente a la calle Cerrajeros número 20 al 28, propiedad de don Manuel Reig Bonell, personaje que aparece como sucesor de Miguel Gómez Prósper en el famoso comercio conocido como Las Ollas, situado en una calle paralela a El Siglo Valenciano. A falta de información, desconocemos cuándo se dio paso al cambio de propiedad entre Jorge Miralles y Manuel Reig Bonell o si figuraban como socios en la empresa.

5 Archivo Histórico Municipal de Valencia (AHMV). Serie: Policía urbana, año: 1867, caja: $104, \mathrm{n}^{\circ}$ expediente: 34 .

6 todocoleccion.net

7 Archivo Histórico Municipal de Valencia (AHMV). Serie: Policía urbana, año: 1901, caja: $3, n^{\circ}$ expediente: 150 .

${ }^{8}$ En 1816 la Real Academia de San Fernando establecerá cuatro categorías; el académico o profesor, el arquitecto, el maestro de obras (actual aparejador), el aparejador (actual encargado de obras). A pesar de las modificaciones, la Academia irá perdiendo poder en pos de la tecnología (1844) y más tarde de la ingeniería, al abandonar las construcciones los conceptos estéticos, formales e ideológicos en pos de la industria, Kostoff, Spiro (cord.). El arquitecto: historia de una profesión, Cátedra, 1977. Fusco, Renato, Historia de la Arquitectura Contemporánea, Celeste Ediciones, 1993. 


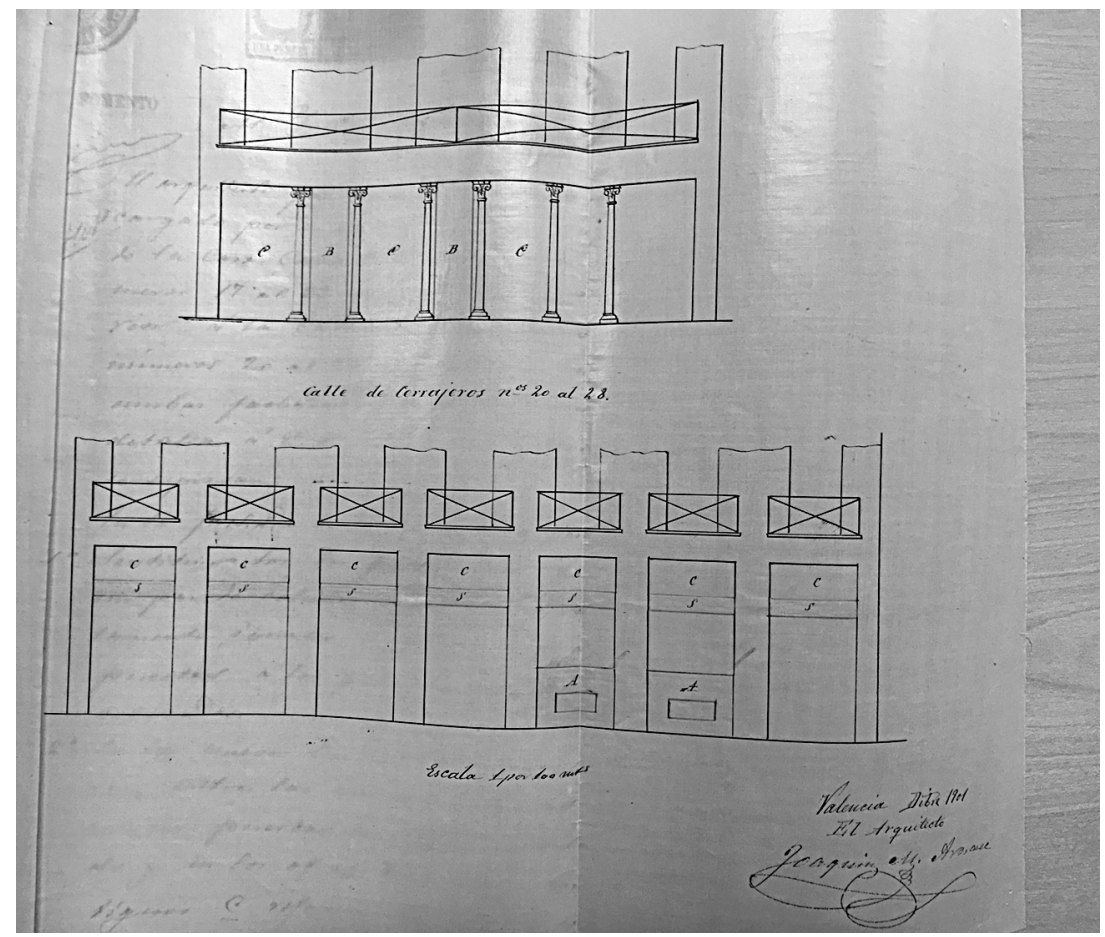

Imagen 8. Fachadas calle san Fernando y calle Cerrajeros. Joaquín María Arnau Miramón, 1901. Fuente: AHMV.

Las remodelaciones que solicita el arquitecto Joaquín María Arnau son las siguientes: en la fachada de la calle de San Fernando según vemos en el alzado adjunto al documento, en la imagen 8 (arriba):

$1^{\circ}$ Sustituir los dos postes $\underline{B B}$ por un par de columnas cada uno, exactamente iguales e igualmente dispuestas a las que ya existen colocadas.

$2^{\circ}$ En los nuevos huecos que resultarán entre las nuevas columnas colocar puertas de acero ondulado y en los otros tres sus contiguos $\underline{\mathrm{C}}$ reformar los cierres existentes, sustituyéndolos por otros de plancha ondulada.

En la imagen 8 (arriba) apreciamos como el total de columnas de fundición ${ }^{9}$ de orden jónico para la fachada de la calle de San Fernando serían seis; es decir,

\footnotetext{
${ }^{9}$ Aunque en este documento no se especifica que fuesen columnas de fundición, otra fuente archivística de 1953, y que expondremos más adelante, nos lo corrobora.
} 
se añadirían cuatro (las sitas de izquierda hacia dentro), por lo tanto, ya existían dos columnas de hierro antes de 1901.

En la fachada de la calle Cerrajeros acometen dicho propósito constructivo, conforme a la imagen 8 (abajo):

$3^{\circ}$ Quitar los antepechos A y las claraboyas $\underline{C}$ en los huecos de planta baja, cortando las soleras $\underline{\mathrm{S}}$ a fin de convertirlos en siete puertas iguales.

$4^{\circ}$ Colocar 4 cierres metálicos en cuatro de los siete huecos que no los tienen y reformar los existentes en los otros tres que ya existen.

$5^{\circ}$ En ambas fachadas reparar los aleros y cornisas de coronación.

De tal manera la planta baja del edificio queda dispuesta con uniformidad en siete puertas de acceso por la calle Cerrajeros.

Este documento estudiado, y sobre todo, el siguiente perteneciente al 29 de marzo de $1902^{10}$, son los decisivos para entender el verdadero momento en el que El Siglo Valenciano se convierte en un almacén dispuesto con una tipología inspirada en los modelos de los grandes almacenes parisinos que buscan espacio, estructura y luz.

En 1902, D. Joaquín María Arnau pide permiso para reformar el interior de la casa número 17 al 23 calle de San Fernando, "cuya finca se dice de la propiedad de don Manuel Reig”. Se adjunta planta en el documento de la imagen 9:

$1^{\circ}$ Abrir un patio de luces central m. n. p. q. en vez de los varios que existen.

$2^{\circ}$ Colocar columnas de fundición en vez de los pilares que hay existentes removiendo para este efecto los entramados de suelo en sus tres pisos todo ellos dentro del área a. b. c. d. e. f. g. sin tocar a las crujías de fachadas que no se alteran.

Sobre el plano vemos diez columnas de fundición añadidas en planta, el color carmín en el plano original delimita los espacios y elementos nuevos. Las transformaciones propuestas en 1902 por Arnau Miramón para El Siglo Valenciano permitían una comunicación visual directa entre las distintas partes del edificio distribuido en tres galerías superpuestas con columnas de hierro fundido, con un punto central que generosamente radiaba y ventilaba los encuentros comerciales, siguiendo los modelos propuestos por Serrano (2006) a modo de hall-plaza. El gran patio crea un espacio diáfano en el medio del recinto, tal y

${ }^{10}$ Archivo Histórico Municipal de Valencia (AHMV). Serie: Policía urbana, año: 1902, caja: $10, \mathrm{n}^{\circ}$ expediente: 513 . 
como se conserva en la actualidad, con una gran claraboya que permite la iluminación simbólica ${ }^{11}$ sobre el bajo y las tres alturas de galerías abiertas delimitadas por rejerías a modo de balaustrada. Este modelo constructivo es heredero directo de la tradición parisina haciendo un giño a las estructuras de generosas techumbres de vidrieras de grandes almacenes como el primitivo Bazar de l'Industrie (1830), la Samaritaine, el gran bazar de la Rue de Rennes, los Bon Marché, Au Coin de Rue o el hall de Printemps, edificados siguiendo los preceptos constructivos del Art Nouveau, empleando elementos estructurales internos caracterizados por la arquitectura del hierro junto a metal visto en sus exteriores, y el vidrio; al igual que se disponen ornamentaciones porcelánicas polícromas en algunos casos como en la Samaritaine.

Como se está viendo hasta ahora el empleo del hierro y del vidrio en la arquitectura, a partir de 1850, será habitual, y con el devenir del tiempo responsable del progreso universal de la misma. Nuevamente, las intervenciones acometidas en El Siglo Valenciano en $1906^{12}$, según fuentes de archivo, reafirman esta idea; véase el alzado de la imagen 10:

El arquitecto Joaquín María Arnau encargado por D. Manuel Reig dueño de la casa calle de San Fernando números 18 al 23 de reforzar la segunda crujía a partir de la calle de Cerrajeros, con el objeto de convertir en almacén los altos de dicha crujía [...] a este efecto se debe colocar en los tres pisos una línea de jácenas con soportes de fundición intermedios a los puntos de fuerza, que hay limitan dicha crujía en la forma que señalan los dos adjuntos planos.

El motivo de reforzar la fábrica nos indica el progreso del negocio ya que necesita estos soportes -colocados en la planta baja, el piso principal y piso segundo-, para sustentar el peso de nuevas mercancías en el tercer piso, siendo el elemento constructivo el hierro fundido, seguro, barato, símbolo de progreso y de la modernidad.

En cuanto a la prensa de fundición, hemos hallado la marca en una de las columnas del primer piso con el cuño Donnay Hijos Valencia. A finales de 1840, la familia Donnay se establecerá en la capital del Turia para dedicarse a la fundición (Álvarez, Ballester, García, Ferrer y Climent, 2001, p. 31), indus-

${ }^{11}$ Primigenias arquitecturas emplean la luz como símbolo, por ejemplo, en época de Constantino, en la Iglesia de la Natividad de Belén, s. IV, el opaion del techo se establece como un eje simbólico donde la luz, que es el cielo, atraviesa el óculo central del cuerpo octogonal del martyria e irradia simbólicamente hacia la gruta donde supuestamente nació Jesucristo, la tierra.

12 Archivo Histórico Municipal de Valencia (AHMV). Serie: Policía urbana, año: 1906, caja: $18, \mathrm{n}^{\circ}$ expediente: 209. 


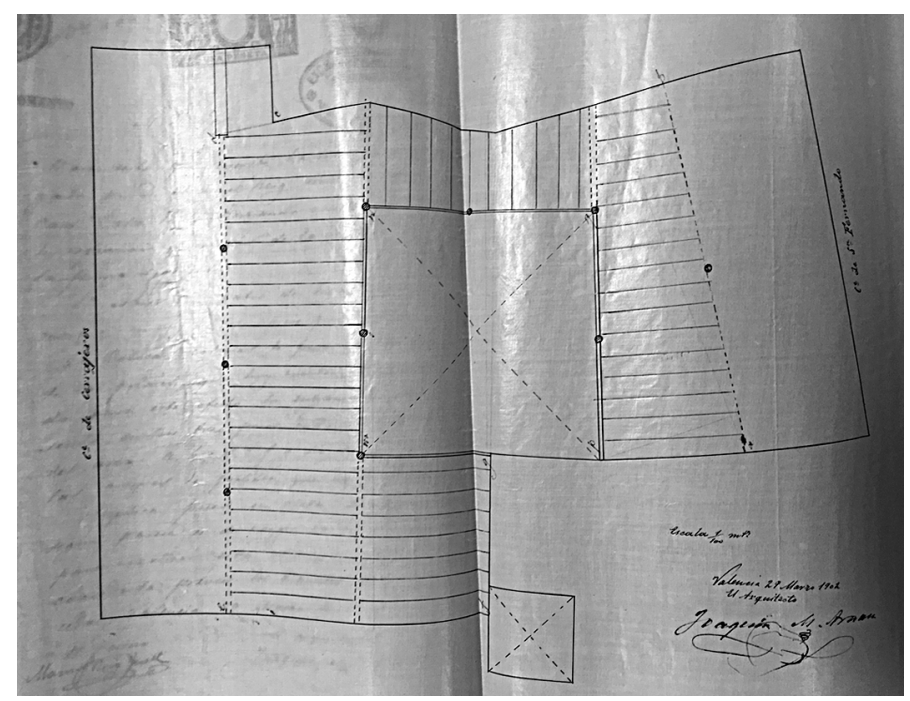

Imagen 9. Plano del almacén El Siglo Valenciano. Joaquín María Arnau Miramón, 1902. Fuente: AHMV.

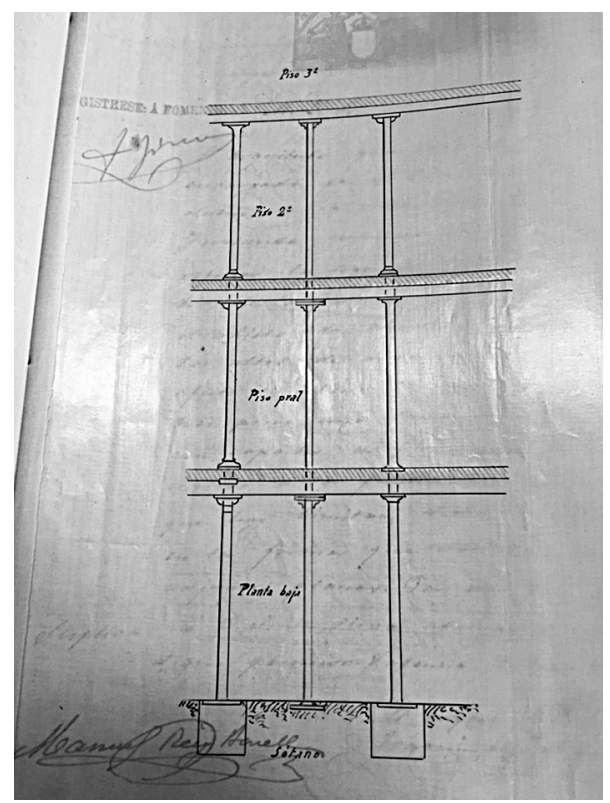

Imagen 10. Línea de jácenas con columnas de fundición. Joaquín María Arnau Miramón, 1906. Fuente: AHMV. 
tria importante en la Valencia del siglo XIX. En 1864, cuando Lamberto Donnay funda La Maquinista Belga, Donnay e Hijos funcionaba paralelamente bajo la supervisión de Juan y Antonio hijos de Lamberto, y a la vez socios con su tío Víctor Donnay (Álvarez et al., 2001, p. 31).

Otro plano de esta misma intervención proyectada en 1906 nos revela información muy valiosa sobre el edificio (imagen 11). En este la entrada principal con una escalera centralizada todavía se haya en la calle Cerrajeros en 1906. Encontramos otra escalera a mano izquierda en el plano y a mano derecha se ubica un temprano ascensor. Desconocemos la fecha de colocación de este primitivo ascensor en El Siglo Valenciano, por falta de documentación, pero sospechamos que junto con el del Pasaje Ripalta sería de los primeros en emplazarse en la ciudad de Valencia, puesto que en ambos edificios trabaja el mismo arquitecto, Joaquín María Arnau Miramón.

En obras presentadas el 20 de mayo de $1912^{13}$ aparece en el archivo (imagen 12) el nombre de otro arquitecto: Luis Ferreres Soler (Xàtiva 1852 - Madrid 1926).

El arquitecto que suscribe [...] la casa $n^{\circ} 25$ y 27 de la calle de San Fernando, para unirla a la contigua $\mathrm{n}^{\circ} 17$ al 23, del mismo propietario y dar ensanche al almacén llamado "El Siglo"14 [...] quitar las escaleras actuales desmarcadas en el plano adjunto con tinta amarilla [centro y derecha arriba] sustituyéndolas por las señaladas en el mismo en tinta carmín [sitas a la izquierda, y que son las actuales], lo cual ha de construirse de nuevo derribando al efecto las secciones correspondientes de los entramados corriendo estos en lo que comprenden las escaleras que han de derribarse o sean: la de un solo tramo de la parte anterior que sirve para bajar a los sótanos; la del fondo o contigua a la calle Cerrajeros que comunica el piso bajo con el $1^{\circ}$ y la situada en el ángulo de la medianera izquierda, que va desde el primer piso a $\operatorname{los} 2^{\circ}$ y $3^{\circ}$.

$\mathrm{Al}$ desaparecer estas escaleras y correrse los respectivos entramados habrán que colocarse un total de 17 viguetas de suelo.

Además, se han de construir los retretes que con carmín se indican en el plano que se acompaña, advirtiendo que lo que expresa el dibujo se refiere a la planta baja [habitáculo cuadrado próximo a la nueva escalera] y que en los pisos altos solo ha de construirse la galería contigua a la escalera con un wáter closset en cada uno de los pisos $1^{\circ}, 2^{\circ}$, y $3^{\circ}$.

13 Archivo Histórico Municipal de Valencia (AHMV). Serie: Policía urbana, año: 1912, caja: $8, \mathrm{n}^{\circ}$ expediente: 5284 .

${ }^{14}$ En este documento aparece por primera vez la denominación del gran almacén como "El Siglo", sin embargo, las fuentes documentales de hemeroteca confirman esta denominación con anterioridad como la propaganda apaisada, que ocupa toda la página número 166, del Almanaque de Las provincias para 1904 (BIVALDI). 


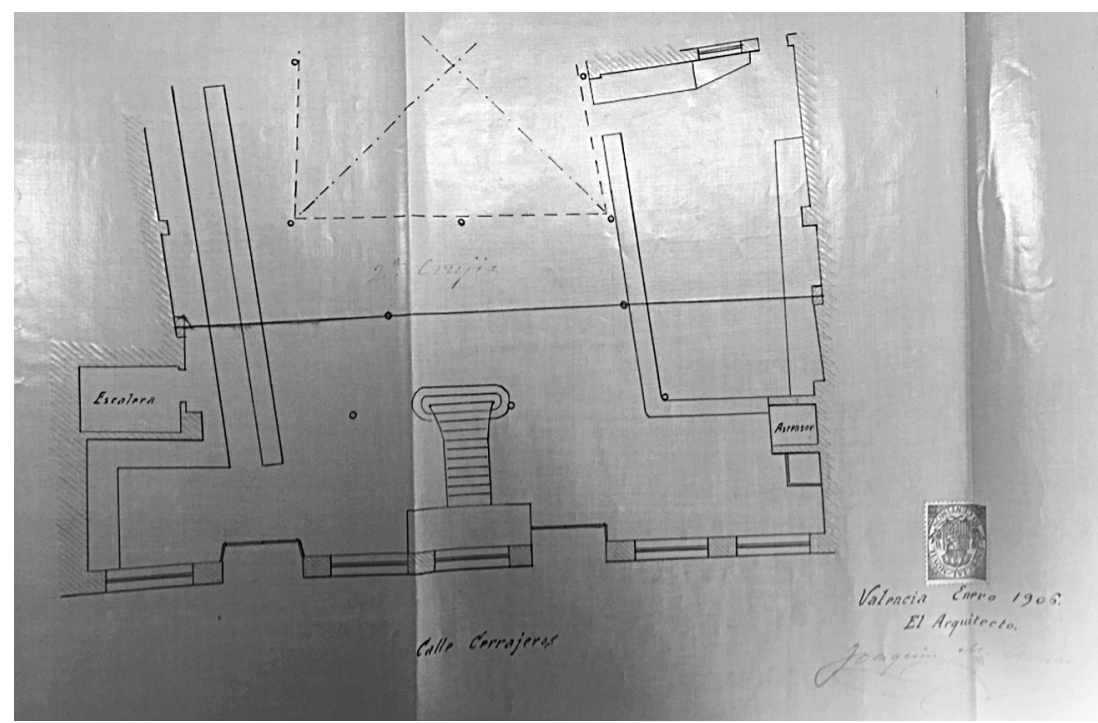

Imagen 11. Plano, línea de jácenas y columnas de hierro en carmín en el plano original. Joaquín María Arnau Miramón, 1906. Fuente: AHMV.

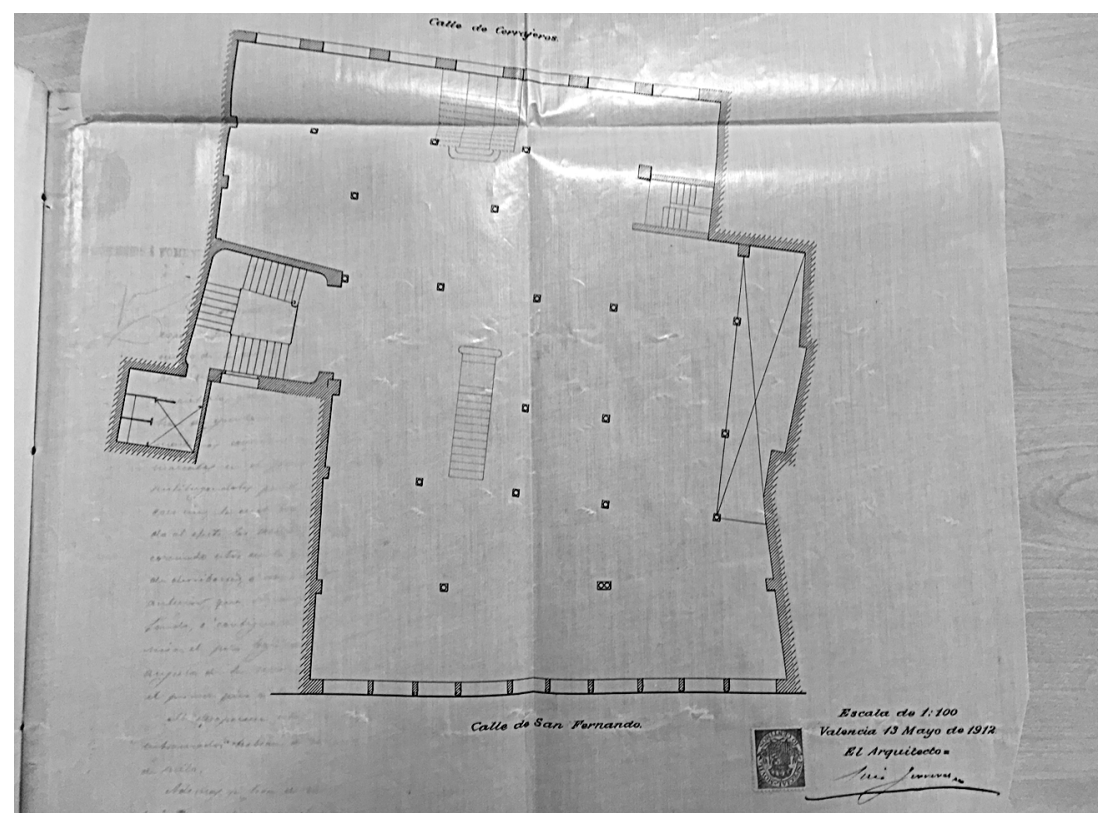

Imagen 12. Plano planta baja, escaleras nuevas y retretes en carmín en el plano original. Luís Ferreres, 1912. Fuente: AHMV. 


\section{0 \\ 6randes filmacenes}

de Tejidos

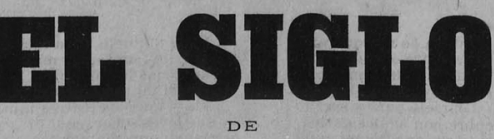

Bernardo Gómez

VALENCIA

Esta importante casa

ha montado tres nue=

vas secciones de PERFUMERIAA

ZAPATERIAA

y ROPA BLANCA CONFECCIONADA

Calle San Fernando, del 17 al 23.

Calle Cerrajeros, del 26 al 28.

Imagen 13. Publicidad El Siglo. Fuente: Almanaque de Las Provincias para el año 1912, p. 111. BIVALDI.

Este documento nos facilita el momento en el que las escaleras actuales se emplazaron en el lugar que hoy en día se encuentran en el edificio. En fuentes fotográficas de principios de $1900^{15}$ vemos todavía las antiguas escaleras centrales que comunicaban la planta baja con el sótano y que quedan dibujadas en el plano (imagen 12).

En esa misma fuente óptica de archivo el comercio se presenta como "Grandes almacenes de tejidos y talleres de confección". En 1912 El Siglo Valenciano se publicita (imagen 13), a manos de Bernardo Gómez ${ }^{16}$, empleando la totalidad de la página del periódico -lo cual indica su bonanza económica-,

15 Biblioteca Valenciana Digital (BIVALDI), "Grandes almacenes de tejidos y talleres de confección El Siglo", Tarjeta postal.

${ }^{16}$ Según Fernández e Ibáñez (2017), en 1879 Bernardo Gómez Igual inauguró El Siglo. 
como grandes almacenes de tejidos pero además anunciando sus nuevas tres secciones de perfumería, zapatería y ropa blanca confeccionada ${ }^{17}$. Como dato añadimos que en 1893 se hace propaganda un almacén de tejidos de seda de Bernardo Gómez ${ }^{18}$ en la calle Calabazas, cercana a la ubicación de El Siglo Valenciano $^{19}$, por lo que posiblemente por oficio y proximidad se trate de la misma persona.

Como hemos comprobado hasta ahora, existía una relación comercial entre los tres apellidos aquí mencionados: Miralles, Reig y Gómez con el negocio El Siglo pero que no hemos podido determinar por falta de prueba registral. En 1914 se anuncia un comercio de tejidos en la calle san Fernando n ${ }^{\circ} 24$ y 26 a nombre de Enrique Miralles ${ }^{20}$. Desconocemos si entre el propietario de 1855 D. Jorge Miralles y esta empresa existía algún tipo de relación o el apellido es mera coincidencia.

En $1931^{21}$, otro documento de archivo testifica la intervención del arquitecto Javier Goerlich Lleó (1886-1972), todavía siendo propietario Manuel Reig Bonel1 ${ }^{22}$, quien pide permiso para realizar obras en la calle San Fernando $\mathrm{n}^{\mathrm{o}} 12^{23}$ : "Sustituir un machón de fábrica del sótano por una columna de hierro, cambiando por pieza de hierro las soleras o dinteles hoy existentes y construir una escalera que comunique la planta baja, con el aludido sótano [...]".

Aunque actualmente esta escalera no ha llegado hasta nosotros, el plano muestra dos entradas desde la calle San Fernando, la escalera proyectada hasta la planta baja, y la colocación de la columna de fundición; véase la imagen 14.

17 Biblioteca Valenciana Digital (BIVALDI), Almanaque de Las Provincias para 1912, p. 110 .

${ }^{18}$ Biblioteca Valenciana Digital (BIVALDI), Guía biográfica, comercial e industrial / número 1 - mes enero, año 1893.

19 Varios eran los establecimientos, contando el famoso gran almacén El Siglo de Barcelona -que en su propia propaganda rezaba: "Los almacenes El Siglo no tienen sucursales ni representantes en ninguna localidad de España ni en el extranjero" (BIVALDI), Almanaque de Las Provincias para 1898, p. 164-, que llevan este mismo nombre en Valencia: camisería El Siglo XX en la desaparecida calle Zaragoza, o horchatería El Siglo y el café El Siglo (BIVALDI).

${ }_{20}$ Anuario Batllés. Región Valenciana, 1914, p. 445. Biblioteca Nacional de España (BNE).

${ }^{21}$ Archivo Histórico Municipal de Valencia (AHMV). Serie: Policía urbana, año: 1931, caja: $21, \mathrm{n}^{\circ}$ expediente: 117.

${ }^{22}$ Este documento nos informa de la dirección del propietario: calle Pascual y Genís número 24 de Valencia.

${ }^{23}$ La dirección del emplazamiento del local es ya el actual: calle San Fernando no 12. 
En $1953^{24}$ se realizan obras de gran importancia de la mano del arquitecto D. Vicente Momfort Romero ${ }^{25}$. Bernardo Gómez, S.L, representada por D. Jesús Gómez Escardó ${ }^{26}$, pide permiso para ejecutar diferentes obras que realcen el interior y el exterior "del edificio conocido por El siglo valenciano, sito en calle de San Fernando 12, con fachada posterior a la calle de Cerrajeros". En la memoria descriptiva dice así:

Este edificio, como es sabido, es una antigua casa comercial con cuatro plantas de amplia proporción, que goza de popularidad -por su emplazamiento, disposición y época de fundación. La estructura del edificio (aunque disimétrica en la disposición de sus pilares de fundición) acusa solidez, como también los espesores de las fachadas. Respetando la estructura se trata de acondicionar la fachada a la calle San Fernando, la portada de planta baja de la calle Cerrajeros y las obras de decoración interior dando una nueva disposición a las vitrinas.

La fachada a la calle de San Fernando tiene actualmente un conjunto inarmónico, ya que tanto el tamaño de los huecos, corrido de molduras, edad del edificio, escasa nobleza de los materiales y deficiente conservación, no resulta adecuada a la finalidad obligada en la actualidad para un edificio comercial (el único en Valencia de estas proporciones) que resalta por defecto, de las modernas instalaciones comerciales en esta zona de la ciudad. Esta fachada se picará y revocará de nuevo; Se estucará con acarreos horizontales con estuco de tipo piedra de Novelda. La cornisa superior será con perfil clásico de piedra artificial. La carpintería de madera en los pisos será sustituida por carpintería metálica sobre antepechos de fábrica de ladrillo de $50 \mathrm{~cm}$. de altura sobre el nivel de cada piso. Dicha carpintería metálica llevará montante fijo en la parte inferior y laterales, dos hojas practicables y un montante basculante a 45 grados para ventilación directa en la parte superior. La planta baja irá tratada con el mismo sentido decorativo que se imprime al conjunto y se revestirán las columnas de fundición existentes, con la finalidad de tapar los capiteles de dichas columnas, que no guardan ninguna relación con el conjunto arquitectónico y están carentes de sentido clásico. Este recubrimiento obliga a que la portada (en el espacio que ocupan estos elementos sustentantes) salgan de la línea de fachada unos $5 \mathrm{cms}$. Los materiales que se emplearán para las nuevas vitrinas serán luna con montantes de metal y mármol. Las columnas serán pulidas en color oscuro y serán visibles los dos tercios de sus diámetros en el fuste. La mencionada fachada tendrá la sencillez y empaque comercial propia de la categoría que le corresponde.

${ }^{24}$ Archivo Histórico Municipal de Valencia (AHMV). Serie: Policía urbana, año: 1953, caja: $14, n^{\circ}$ expediente: 43505 .

${ }^{25}$ Según el documento de archivo, vivía en la calle Pedro III el Grande nº 9 de Valencia.

${ }^{26}$ Jesús Gómez Escardó, de Valencia, domiciliado en la Avenida del Barón de Cárcer $\mathrm{n}^{\circ} 40$ fue el fundador de Monte Picayo. 


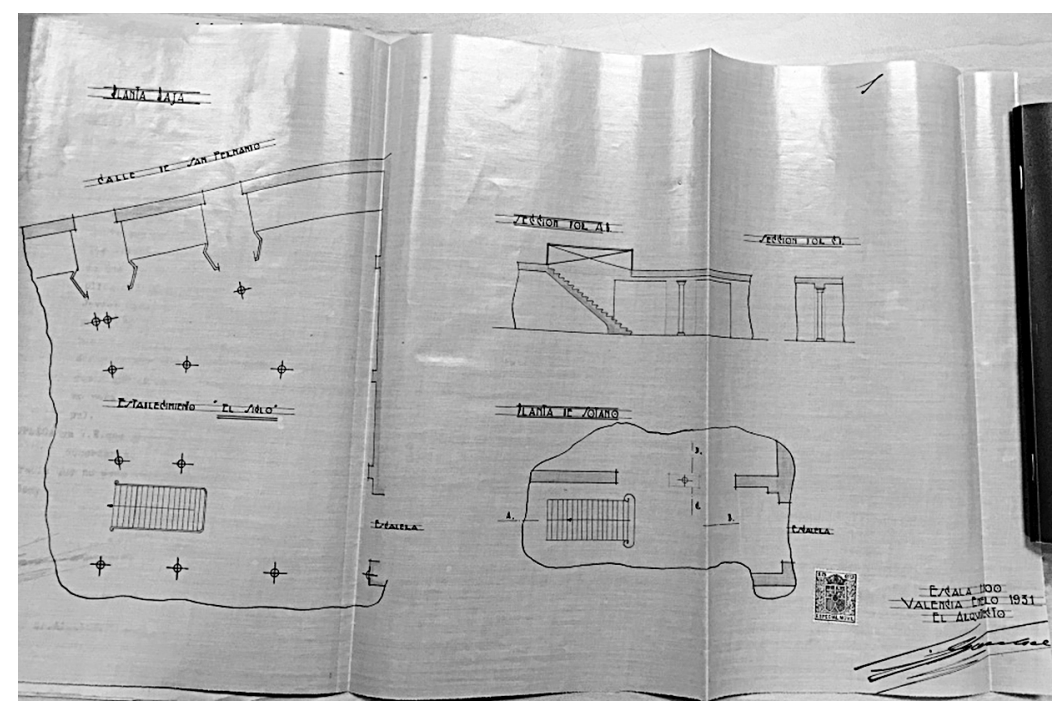

Imagen 14. Plano almacenes El Siglo Valenciano. Javier Goerlich, 1931. Fuente: AHMV.

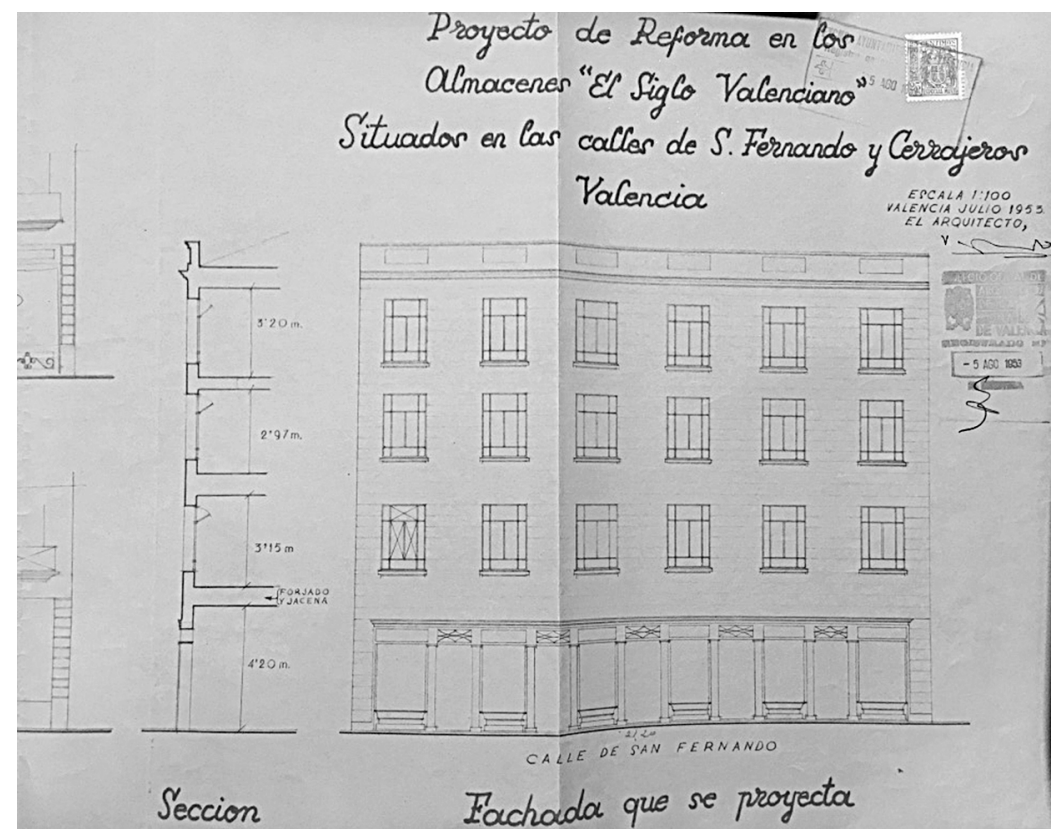

Imagen 15. Fachada que se proyecta calle san Fernando. Vicente Momfort, 1953. Fuente: AHMV. 
El documento continúa diciendo:

La portada de la calle Cerrajeros [Imagen 16] se limpiará y conservará los modillones existentes; se cambiará el acceso situándolo en el hueco central y el resto de los huecos serán vitrinas. El conjunto de esta portada se decorará con cerrajería artística, azulejería valenciana, etc., con la finalidad de dar a su conjunto el carácter de su emplazamiento.

El número de accesos a la planta baja serán cuatro, uno por la calle Cerrajeros y tres por la calle de San Fernando.

Se completarán las obras con las correspondientes de decoración interior, pintura, etc., propias del caso; todo ello con buenos materiales y esmerada mano de obra y con arreglo a los planos que se acompañan y a la presente memoria.

Se instalará un nuevo ascensor.

El presupuesto inicial de las obras asciende a la cantidad de 150.000 pesetas.

En 1950, en Valencia, entra la influencia del Segundo Movimiento Moderno, de influjo madrileño, en la arquitectura. En este contexto, el arquitecto Vicente Momfort Romero, en 1953, con la estructura resuelta a través de un entramado metálico, presentará un proyecto de remodelación siguiendo dichas pautas, este proyecto trae en sí que la fachada formará parte de los bajos, integrando el almacén con la calle, y al viandante para ello. Se depura el elemento decorativo, por lo que se eliminará la decoración, aún existente en la calle Cerrajeros.

Con respecto al ascensor que nombra la memoria, vemos en el plano (imagen 17) señalado en carmín (extremo superior izquierdo del plano) el ascensor que ya encontrábamos en 1906. Seguido de este se dibuja un montacargas en carmín (por lo tanto nuevo), y correlativo se esboza otro "montacargas al sótano" -pues no aparece en el primer piso según plano (imagen 18)- que no va coloreado de rosa. Concluimos que, en 1953, todavía no estaba colocado el ascensor en el sitio que en la actualidad lo encontramos; y que el ascensor que instalan nuevo ocupa el mismo hueco que el precedente de 1906, y, por lo tanto, es una sustitución de este.

En este documento aparece emitiendo el informe de conformidad la denominada:

Comisión Mixta para la conservación de la Zona Histórico-Artística quien informa favorablemente del expediente, examinado el proyecto en su aspecto estético, encontrándolo con dignidad suficiente y amoldado al res- 


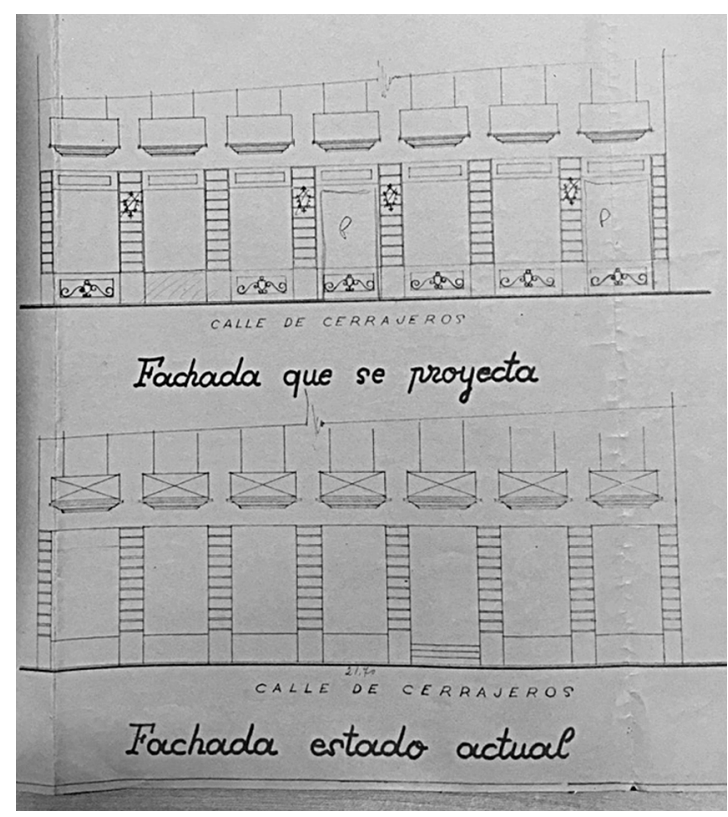

Imagen 16. Fachada que se proyecta y actual calle Cerrajeros. Vicente Momfort, 1953. Fuente: AHMV.

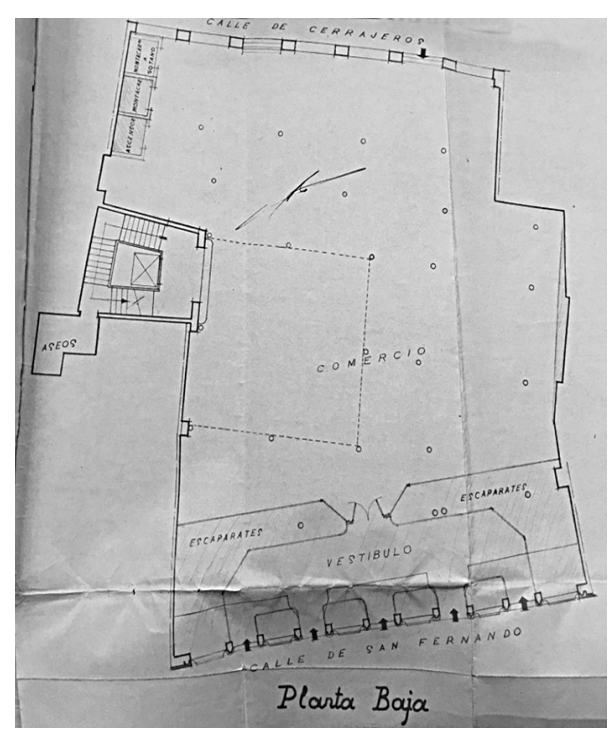

Imagen 17. Plano de la planta Baja. Vicente Momfort, 1953. Fuente: AHMV.

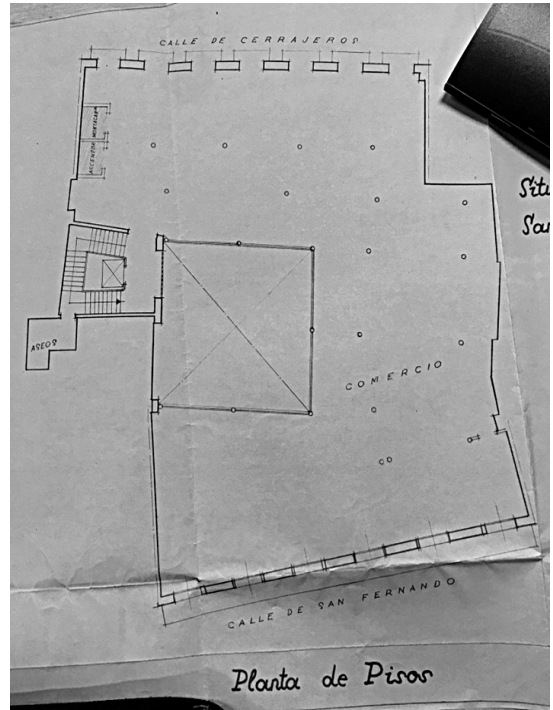

Imagen 18. Plano de la planta de pisos. Vicente Momfort, 1953. Fuente: AHMV. 
pectivo carácter de las dos fachadas [...] las obra [...] se hallan acuerdo con las alineaciones que figuran en el plano de alineaciones y zonificación correspondientes al Sector de su emplazamiento...

Manzana edificable en toda su profundidad. Zonificación: Recinto antiguo Histórico-Artístico. Ancho calles: San Fernando 6,00 mts. Cerrajeros $4,50 \mathrm{mts}$.

En este mismo expediente, en 1956, doña Josefina Reig Martín, doña Carolina y doña María Eugenia Reig Martín dan parte de que no han concedido su autorización para realizar dichas obras según los "autos de resolución de contrato de arrendamiento de local de negocio, contra la compañía mercantil Bernardo Gómez S.L. cuyo establecimiento gira bajo la denominación comercial de El Siglo Valenciano [...]".

Con esta última noticia de archivo sobre El Siglo Valenciano cerramos, a falta de la aparición de nuevos datos, este apartado de recorrido histórico, no sin antes añadir que fruto de esta sociedad decimonónica, muestra del modelo social y cultural que se está viviendo, es el fresco situado en la primera planta, conservado hoy, atribuido al pintor Fernando $\mathrm{Cabero}^{27}$ que capta la sensibilidad de una época pasada y se convierte en testimonio con su vertiente historicista regionalista de una época que vivió el esplendor del mundo del comercio y la burguesía, con mirada a la gloria del antiguo oficio de la seda, ya que en escena aparecen unas mujeres vestidas de valencianas, ataviadas con ricos trajes de seda del siglo XVIII, a las que un comerciante muestra unas telas junto a unos fardos depositados en el suelo. A mano izquierda contemplamos el mar como referencia al paisaje valenciano y al rico comercio que hubo a través de este, imagen que une la tradición y la modernidad. En una posterior actuación Javier Mariscal (1950) realizará, respetando la obra, una instalación que representa a la ciudad.

Con la aparición en la dedada de los 60 del siglo XX de las grandes superficies en el extrarradio de la ciudad, los grandes almacenes cayeron en decadencia trasladándose a una planta baja, de la misma calle, situada frente al edificio.

${ }^{27}$ El Dr. Pablo Sánchez Izquierdo hace muestra de parte de la obra de Cabero en una de sus investigaciones, Sánchez Izquierdo, P. (2017, Diciembre). La memoria silente. Recepción y recuperación de testimonios plásticos de la represión franquista. Alicante 19361942. Ponencia presentada en Recepción, imagen y memoria del arte del pasado (RIMA). Seminario Internacional de Historia del Arte, Valencia, España. 


\section{CONCLUSIONES}

Los grandes almacenes El Siglo Valenciano se crearon, a partir de la segunda mitad del siglo XIX, con el objetivo de vender tejidos y confección al por mayor y al detall. Con posterioridad a estos productos, en 1914, se incorporaría a la venta artículos de perfumería y zapatería.

En este análisis hemos mostrado los momentos más significativos de la construcción del edificio, identificando de forma inédita el nombre del maestro de obras y de los arquitectos que llevaron a cabo los diversos proyectos con las distintas fechas de construcción y rehabilitación por las que pasó el edificio, que abarcan alrededor de un centenar de años.

Los grandes almacenes El Siglo Valenciano fueron una nueva forma de entender la arquitectura al servicio del comercio. Los métodos de construcción junto al empleo del hierro y del vidrio consiguieron lo que se buscaba: espacio, estructura y luz. Como fortaleza a su favor, el establecimiento estuvo emplazado en el centro neurálgico comercial de la ciudad, con fácil acceso de comunicación, apoyado por los nuevos planes urbanísticos y las recién trazadas líneas del tranvía.

No hay que olvidar, en el buen desarrollo del negocio de los grandes almacenes, la Revolución Industrial y el papel de las fábricas de bienes de consumo que facilitaron objetos y prendas de calidad de toda índole a bajo coste en un mismo punto de encuentro, como fue en el caso de los almacenes aquí estudiados. El nacimiento de las clases medias que empezaron a profesionalizarse será otra de sus fuerzas, ya que favorecerán una sociedad de consumo de masas donde los medios de comunicación y las artes gráficas publicitarias con su mensaje -todavía tipográficos en su mayoría aunque con algún elemento litográfico decorativo-, ejercerán un papel decisivo en el ámbito comercial.

En la actualidad, la estructura interior ha mantenido el espacio tal y como lo concibió el arquitecto Joaquín María Arnau Miramón, en 1902. La disposición se divide en $3.500 \mathrm{~m}^{2}$, en cuatro plantas diáfanas, y un sótano, además de las dos entradas por la calle San Fernando y la calle Cerrajeros. La terraza ha sido adecuada para celebrar eventos.

En cuanto a la arquitectura del hierro del espacio interior, los antepechos de hierro dispuestos en cada piso a modo de balaustrada se han mantenido originales, con probabilidad colocados en la reforma de 1902 cuando se construye el gran vano diáfano central, obra del arquitecto Arnau Miramón. Las columnas de fundición sitas en los extremos que recorren todo el perímetro del gran vano principal, desde el primer piso al tercero, no mantienen los capiteles jónicos que podemos ver en fuentes ópticas conservadas de principios del siglo XX. 
Hoy en día, determinamos varios tipos de capiteles en las columnas de fundición dispuestos por todo el edificio.

Por otro lado, la fachada de la calle San Fernando de solución funcional y fabril, con un eje de simetría de ventanas adinteladas ordenadas en calles horizontales como arquitectura lineal y geométrica con ejes de simetría, presenta una estructura de grandes ventanales acristalados que permiten la entrada de la luz y una buena ventilación. La fachada de la calle Cerrajeros mantiene la misma estructura de la reforma de 1860, tres alturas y bajo con siete vanos cada una.

La labor de restauración ha sido llevada a cabo por diversas entidades involucradas en el rescate de este singular edificio dándole un nuevo uso. La iniciativa de conservación y restauración del patrimonio se encaró con un doble objetivo: convertirse en un elemento vivo de cultura, como sede de entidades y como centro de actividades, al tiempo que se recuperó para la ciudadanía un edificio con reconocida relevancia histórica, artística y social, convirtiéndose desde el año 2006 en Octubre Centre de Cultura Contemporània (OCCC).

\section{BIBLIOGRAFÍA Y FUENTES}

\section{FUENTES}

AHMV= ARCHIVO HISTÓRICO MUNICIPAL DE VALENCIA, Serie: Policía urbana, año: 1855 , caja: $83(100), n^{\circ}$ expediente: 47 , año: 1866 , caja: $103(128), n^{\circ}$ expediente: 89 , año: 1867 , caja: $104, n^{\circ}$ expediente: 34 , año: 1901 , caja: $3, n^{\circ}$ expediente: 150 , año: 1902 , caja: $10, \mathrm{n}^{\circ}$ expediente: 513 , año: 1906 , caja: $18, \mathrm{n}^{\circ}$ expediente: 209, año: 1912, caja: $8, \mathrm{n}^{\circ}$ expediente: 5284 , año: 1931 , caja: $21, \mathrm{n}^{\circ}$ expediente: 117, año: 1953, caja: $14, \mathrm{n}^{\circ}$ expediente: 43505.

BIVALDI= BIBLIOTECA VALENCIANA DIGITAL, Guía biográfica, comercial e industrial / número 1 - mes enero, año 1893; La Semana Gráfica. Revista ilustrada semanal de la región de Levante, año V, número 163 - 24 agosto 1929; Almanaque de Las Provincias para el año ... : la vida valenciana en el año: año 1896, 1904 y 1914. BNE= BIBLIOTECA NACIONAL DE ESPAÑA, Anuario Batllés, 1914; La Ilustración española y americana, junio 1872 y diciembre 1873; Tarjetas y prospectos de productos y establecimientos comerciales, 1880/1900.

\section{BIBLIOGRAFÍA}

AGUILAR, I. (1990): El orden industrial en la ciudad. Valencia en la segunda mitad del siglo XIX, Valencia, Historia Local/ 5, Diputación de Valencia, 53 p.

ÁLVAREZ. A., BALLESTER. B., GARCÍA. C., FERRER. M. y CLIMENT. S. (2001): Valencia Industrial: Las fundiciones, Valencia, Ajuntament de València. 
BASSEGODA, J. (1974): Los Maestros de obras de Barcelona. Barcelona, Editores técnicos asociados, $\mathrm{S}$. A.

BENITO, D. (1992): La Arquitectura del Eclecticismo en Valencia, Valencia, Ajuntament de València.

BENJAMIN, W. (2005): Libro de los Pasajes, Madrid, Akal, 51 y 60 p.

CALLADO, E. (2014): Mujeres en clausura. El convento de Sta. María Magdalena de Valencia, Valencia, Universitat de València, 292 p.

CERDÁ, M. y GARCÍA, M. (1995): Enciclopedia Valenciana de Arqueología Industrial, Valencia, España, Edicións Alfons el Magnànim, 592 p.

DE FUSCO, R. (1993): Historia de la Arquitectura Contemporánea, Madrid, Celeste Ediciones.

FERNÁNDEZ, G. y IBÁNEZ, E. (2017): Comercios históricos de Valencia, Catarroja, España, Vinatea Editorial, 304 p.

GONZÁLEZ-VARAS, I. (2008): Conservación de bienes culturales. Teoría, historia, principios y normas, Madrid, España, Cátedra, 39 y 345 p.

HERNÁNDEZ, L. (1996): Conocer Valencia a través de su arquitectura, Valencia, Ajuntament de València.

HERNANDO, J. (1989): Arquitectura en España 1770-1900, Madrid, España, Manual Cátedra.

HITCHCOCK, H. (1993): Arquitectura de los siglos XIX y XX, Madrid, España, Manuales Arte Cátedra, $191 \mathrm{p}$.

ISAC, A. (1987): Eclecticismo y Pensamiento Arquitectónico en España, Discursos, Revistas, Congresos 1846-1919, España, Granada, Diputación Provincial.

KOSTOFF, S. (cord.) (1977): El Arquitecto: Historia de una profesión, Madrid, España, Cátedra.

PALACIO, V. (1998): Edad Contemporánea I (1808-1898), Madrid, Espasa-Calpe, $339 \mathrm{p}$.

PINGARRÓN, F. (2005): "Derribos, ventas y destinos de conventos suprimidos de la ciudad de Valencia y de los enajenados entre los años 1837 y 1839”, Ars longa, cuadernos de arte, No. 14-15, 271-301.

QUIRÓS, F., COELLO, F., y GUESDON, A. (1991): Las ciudades españolas a medidos del siglo XIX, Valladolid, Ámbito Ediciones, 24 y 51 p.

ROSELLÓ, V. M. y CAPAPRÍA, J. E. (2000): La Fachada septentrional de la ciudad de Valencia, Valencia, Bancaja.

SÁNCHEZ, P. (2017, Diciembre): "La memoria silente. Recepción y recuperación de testimonios plásticos de la represión franquista. Alicante 1936-1942", Ponencia presentada en Recepción, imagen y memoria del arte del pasado (RIMA), Seminario Internacional de Historia del Arte, Valencia.

SERRANO, R. (2006): “Aspectos urbanos y arquitectónicos de los grandes almacenes de París: Modernización del gran comercio urbano a partir de la primera mitad del siglo XIX”, Scripta Nova, revista electrónica de geografía y ciencias sociales, Vol. X, No. 211, 15 de abril de 2006. 
TABERNER, F. Y BROSETA, M․ T. (2013): “Arquitectura y desarrollo urbano. Notas sobre el Ensanche de Valencia de 1884", Archivo de Arte Valenciano, Vol. XCIV, 181-200.

TEIXEDOR, M. J. (1976): Funciones y desarrollo urbano en Valencia, Valencia, Instituto de Geografía, Institución Alfonso el Magnánimo, Diputación provincial de Valencia, Caja de ahorros y Monte de Piedad de Valencia.

TOBOSO, P. (2002): “Grandes almacenes y almacenes populares en España. Una visión histórica", Historia económica (Fundación SEPI), nº 2.

ZOLA, E. (1999): El paraíso de las damas, Barcelona, Alba Editorial. 